\title{
A variação de tom em texto espontâneo memorizado longo ${ }^{4}$
}

\author{
Marcus V. M. Martins
}

\section{Introdução}

O trabalho "A variação de tom em texto espontâneo memorizado longo" tem por objetivo avaliar, através de análises automáticas da Prosódia, a variação do Tom Médio em Narrativas Orais, visando analisar se existe alguma relação entre esta mesma variação e a estrutura da narrativa. $O$ estudo foi desenvolvido no âmbito do Projeto ExProsodia - Análise automática da entoação na fala de língua portuguesa, integrando-se aos demais trabalhos já desenvolvidos pelo grupo, nas áreas Percepção e Percepção de Prosódia.

Em princípio consideramos como narrativa oral, como qualquer texto com uma duração mais longa do que uma frase e que se componha dos elementos previstos em (LABOV; WALETZKY, 1972; WENNERSTROM, 2001): Resumo, Orientação, Ação complicadora, Resolução, Coda e a Avaliação. Sendo importante ressaltar que estes elementos podem aparecer na ordem como apresentada, ou em ordem diversa, bem como certos elementos podem ser omitidos. Usamo-nos deste modelo, por crermos ser ele o que de modo mais abrangente engloba as vicissitudes de uma narrativa oral. Apoiamo-nos, também, nas

\footnotetext{
${ }^{4}$ 170 SIICUSP - SIMPÓSIO INTERNACIONAL DE INICIAÇÃO CIENTÍFICA/USP. São Paulo, 2009.
} 
propostas de Bruner (1991) no que se refere a "funcionalidade" das narrativas orais, no contexto da psicologia e da sociologia, de modo que a Prosódia poderia ser tomada como um elemento constitutivo deste caráter sócio-psicológico das narrativas orais.

Por Tom Médio (TM) compreendemos como a média dos valores de F0 obtidos em uma dada elocução, de modo que nosso parâmetro acústico para a avaliação da entoação da fala seria a frequência, primeiramente analisada em Hertz e posteriormente covertida em valores de semitons. A análise de tais dados se dá pelo uso da rotina ExProsodia de Análise Automática da Entoação na Fala de Língua Portuguesa (FERREIRA NETTO, 2008), desenvolvida pelo próprio Prof. Dr. Waldemar Ferreira Netto no âmbito do Grupo de Pesquisa ExProsodia. A rotina opera através da decomposição das frequências em componentes estruturadoras (finalização, sustentação) e semântico-funcionais (foco/ênfase, acento lexical). Basendo-se na hipótese de que as variações de entoação, percebidas pelos ouvintes no nível frasal, decorrem da coordenação entre essas componentes. Deste modo, nosso trabalho pretende não ser apenas uma simples análise dos valores TM, em uma dada narrativa oral, mas, sim que a mesma pudesse ser feita de maneira automática pela Rotina, de forma que pudéssemos vir a oferecer subsídios para um melhor desenvolvimento da mesma.

\section{Estudo do Tom Médio em narrativas orais.}

O estudo a cerca do Tom Médio nas narrativas orais pautou-se por duas propostas básicas: uma primeira, que se fez durante a coleta do corpus, previa uma observação da estrutura de tais narrativas de acordo com a proposta de (LABOV; WALETZKY, 1972; WENNERSTROM, 2001), esta análise prévia se fazia necessária para que pudéssemos avaliar se, de fato, haveria algum elemento subjacente as narrativas orais, o qual também 
fosse um elemento estruturador. Neste sentido, esta préanálise não tinha caráter descritivo no que se refere a análise prosódica, apenas o intuito de se organizar as mesmas. A segunda proposta, refere-se a análise prosódica, propriamente dita, isto é se haveria alguma relação entre a variação dos valores de F0, produzidos por um falante em uma situação de narração, com estes elementos estruturais da narrativa oral.

\section{Descrição das atividades}

Dadas tais propostas a coleta de corpus pressupunha uma espontaneidade do discurso. Com o intuito de facilitar a coleta e, principalmente, de evitar que o caráter acadêmico da pesquisa viesse a interferir, optamos por coletar as gravações em sites, como o Youtube, ou em centros de memória e museus de pequenas cidades onde houvesse este tipo de gravação.

A segunda etapa após esta coleta referia-se a transcrição ortográfica e a segmentação das mesmas, uma vez que a Rotina ExProsodia opera com porções menores em sua análise, por uma limitação do programa base, no caso o Microsoft Excel. Desta maneira, a segmentação visava recortar um texto longo, no caso a narrativa oral em parcelas menores, frases. Nosso parâmetro para a segmentação frasal foram os seguintes:

- Orações coordenativas seriam segmentadas nas conjunções;

- Orações subordinativas não seriam segmentadas;

- Discursos indiretos também não seriam segmentados.

Esta segmentação visava recortar o texto em $n$ partes, de modo que pudéssemos prosseguir em nossas análises. A segmentação do áudio foi executada com auxílio do programa Sony Sound Forge 9 Trial Version, em seguida os $x$ trechos colhidos tiveram seus valores de frequência $e$ intensidade analisados pelo 
programa de análise fonética Speech Filling System (doravante $\mathrm{SFS}^{5}$ ) (HUCKVALE et alli,1987). Nesta etapa do processo visamos obter todos os valores válidos de $\mathrm{FO}$ (em HZ) e intensidade (em RMS) dos $n$ segmentos, visando obter os dados subsidiários para o funcionamento da Rotina ExProsodia. Os dados obtidos foram salvos no formato .txt, formato de arquivo, o qual a rotina será capaz de analisar fazendo uma relação entre os valores e qual frame cada valor pertence. Em alguns casos foram feitas transcrições do texto de modo que a rotina irá relacionar os mesmos valores com as respectivas transcrições.

A terceira etapa de nosso trabalho refere-se ao uso da Rotina ExProsodia propriamente dita. Como citado o programa de análise fonética SFS, através de um comando coleta os valores de frequência e intensidade do espectrograma e os ordena, de acordo com sua sequência, em arquivo .txt (Bloco de Notas do Windows). É preciso ressaltar que os valores de frequência a que nos referimos são os valores de $\mathrm{F} 0$, ou seja, da primeira componente da análise de Fourier. A Rotina por sua vez lerá os dados em .txt, na sequência dada pelo programa SFS e fará os cálculos necessários para a análise prosódica, bem como nos fornecera os gráficos de variação dos valores em cada segmentos. Além disso, os valores a serem analisados seguirão parâmetros de frequência, intensidade e duração já préestabelecidos, quer sejam pelo analista, quer sejam valores padrões já fixados pela própria rotina. Desta maneira, se o valor estiver dentro dos limites de máximo e mínimo estabelecidos

\footnotetext{
5 "SFS is not public domain software, its intellectual property is owned by Mark Huckvale, University College London and others. However SFS may be used and copied without charge as long as the programs and documentation remain unmodified and continue to carry this copyright notice." In:

http://www.phon.ucl.ac.uk/resource/sfs/help/overview.htm.
} Acessado em 19 de Janeiro de 2010 
ele será considerado nos cálculos da análise prosódica, caso contrário não.

Para este estudo operamos com valores já programados pela rotina, uma vez que trabalhamos exclusivamente com vozes masculinas:

Frequência operante: inicial de $50 \mathrm{~Hz}$ até $350 \mathrm{~Hz}$, uma vez que trabalhamos exclusivamente com vozes masculinas:

- Intensidade: 470,33 RMS

- Duração das pausas: $100 \mathrm{~ms}$, ou 20 frames.

A mesma operação foi executada em todos os $n$ segmentos obtidos na etapa 2. Feito isto a quarta e última etapa do desenvolvimento, ocupou-se de obter o valor médio de F0 de todos os segmentos, agora convertidos em valores de semitons e apresentados na escala MIDI. Esta etapa visava, primeiramente, à conversão dos valores de Hertz $(\mathrm{Hz})$ para Semitons (st) e à análise do comportamento de Tom Médio de cada segmento, baseado nesta coversão. Os mesmos valores foram agrupados em um gráfico, respeitando a ordem da segmentação, ou seja, os $n$ segmentos foram agrupados na ordem $\left(x_{1}, x_{2}, x_{3} \ldots x_{n}\right)$. Esta ordenação dos dados visava a observar o comportamento do Tom Médio na narrativa como um todo, de modo que os valores obtidos pudessem ser comparados entre si, bem como com um valor referencial, caso fosse necessário. Além disso, procuramos obter os últimos valores de frequência válida de cada segmento (as finalizações, ou tom final) para uma comparação dentre eles.

Análise dos dados

A análise dos dados obtidos até esta etapa foram debatidas e analisadas em conjunto com o professor e os demais orientandos em nossas reuniões semanais. Desta forma, o grupo que se dividia em duas frentes, uma de percepção de fala e outra de produção de fala, poderia analisar seus resultados e 
chegar a conclusões e análises que levassem a concatenar as duas propostas.

Neste sentido, a análise quantitativa obtida pelo grupo do estudo da percepção fornecia subsídios para a interpretação dos dados qualitativos do estudo da produção. Assim como o inverso. A análise de nosso trabalho pautou-se justamente pela coadunação destas duas frentes. $O$ grupo de percepção em seu trabalho "Sensitivity to fo variation in Brazilian Portuguese" (CONSONI et al., 2009) baseado nos estudos de percepção desenvolvidos por T'Hart (1981) para o holandês, concluiu que a variação mínima perceptível para o falante de português brasileiro é de 3 semitons ascendentes e 4 semitons descendentes. $[(x+3),(x-4)]$, sendo $x$, um valor referencial não determinado. Desta forma, em nossa análise nos propomos a fazer uma análise usando-se desta proposta.

Uma questão em que nos deparamos referia-se ao estabelecimento do valor de referência para a análise da variação de TM. A solução melhor encontrada foi a de se calcular o TM geral da elocução. Devido as limitações já expostas não poderíamos ter acesso ao dado puro, deste modo, optamos por fazer o cálculo do TM geral de maneira indireta, i.e. através da média dos valores de TM dos $n$ segmentos. De acordo, com a fórmula1:

$$
t m_{g}=\frac{x_{1}+x_{2}+x_{3}+\ldots+x_{n}}{n}=\frac{1}{n} \sum_{i=1}^{n} x_{i}
$$

Fórmula. 1. Cálculo para Média dos valores de TM

Feito este cálculo para a obtenção do valor de referência, no caso o tom médio geral, podemos usar dos estudos feitos pelo grupo da percepção e ver em quais dos $\mathrm{n}$ segmentos da narrativa oral a variação era $(x+3)$ ou $(x-4)$. Isto é, quais as variações nos discursos do falante seriam realmente percebidas 
pelo ouvinte e qual destas variações seria relevante para a percepção do ouvinte, assim como, se estas variações teriam alguma relação com a estrutura da narrativa propriamente dita.

\section{Análise de Caso:}

Aqui apresentamos os resultados obtidos em nosso teste de hipótese. A narrativa escolhida foi coletada no site Youtube, e conta com 4'56" de duração, além de atender as prescrições de Labov, principalmente no que concerne ao ter uma introdução, uma ação complicadora e uma finalização. Ao segmentarmos obtivemos um total de $8 \mathrm{~g}$ segmentos frasais, de acordo com nossa proposta de segmentação, as quais foram analisadas pelo SFS, assim como pela rotina ExProsodia. Ao agruparmos os dados de TM e Finalização como expostos no gráfico a seguir (os valores estão apresentados em termos de MIDI):

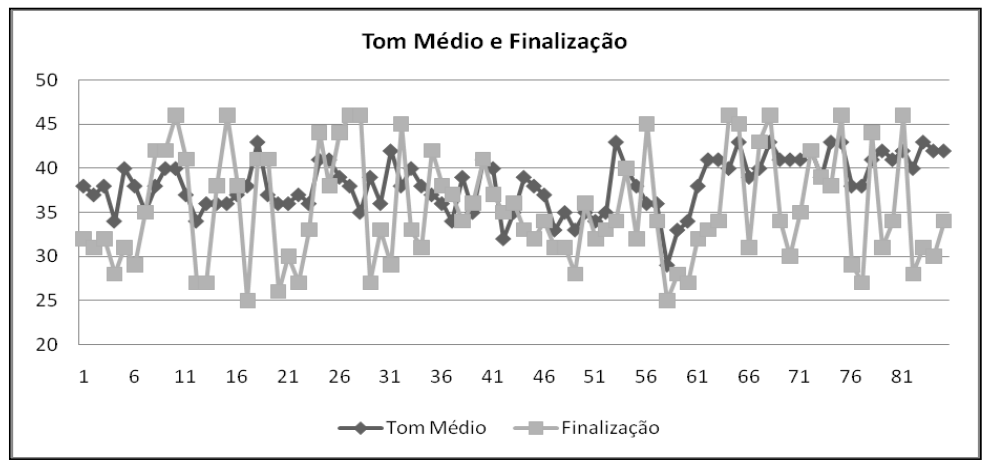

Gráfico 1. Variação de TM e Finalização.

Podemos observar que a correlação entre TM e Finalização é baixo $(p=0,336)$, contudo pode-se dizer que para estudos de fala é um indicador bastante forte da correlação da variação entre as duas grandezas. Obtivemos também, um gráfico (Gráfico2) apenas com os valores de TM, o que, de fato, era o 
que interessava para a nossa pesquisa (os valores estão em termos de MIDI):

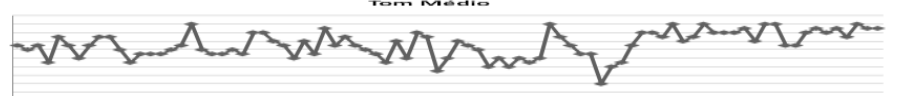

Gráfico 2. Variação de Tom Médio

A partir do gráfico 2 de Variação do Tom Médio, nos fica claro que em certos pontos temos uma variação maior, em comparação ao restante do gráfico, assim como nos fica nítido que os valores têm a tendência a manterem-se em uma faixa de variação praticamente estável. A partir desta observação podemos analisar aquilo que realmente seria uma variação perceptível para um ouvinte. Com base no trabalho "Sensitivity to fO variation in Brazilian Portuguese" e na fórmula 1, pudemos chegar a conclusão de que o valor de referência era 38 , em termos de MIDI e 150, $00 \mathrm{~Hz}$ em termos numéricos, o que equivaleria D2, em cifras musicais. Além disso, fizemos um levantamento quantitativo (Graf.3) visando localizar os valores que mais apareceriam, aplicando-se o cálculo de variação perceptiva $[(x+3),(x-4)]$.

Chegamos a conclusão que os segmentos onde o valor de TM fosse maior que 41 (F2), ou menor que 34 (A\#1), seriam relevantes para a análise da percepção, bem como poderiam ser dicas para a compreensão se a variação do TM nas narrativas orais teriam alguma relação com a sua estrutura. 
Análise quantitativa de tons.

13

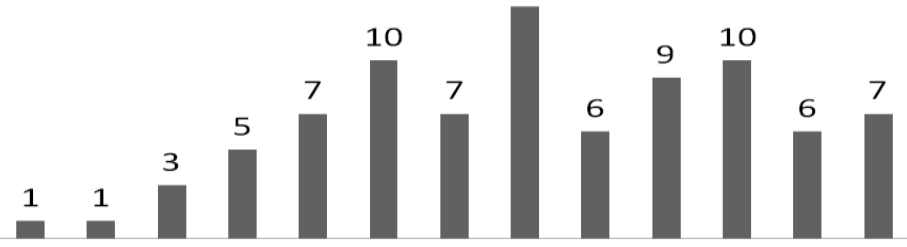

F1 G\#1 A1 A\#1 B1 C2 C\#2 D2 D\#2 E2 F2 F\#2 G2

Gráfico 3. Análise quantitativa dos valores de TM (em cifras)

Podemos ver através deste gráfico que a grande parte dos valores de TM, concentra-se na faixa predita (de 34 a 41; de A\#1 a F2) onde a variação ainda não é perceptível ao falante sendo que um total de 67 de 85 (78,82\%) dos segmentos encontra-se nesta faixa. Entretanto ao retomarmos ao gráfico 2 e aplicarmos o mesmo cálculo percebermos que grande parte das variações perceptivas encontram-se no trecho que compreende os segmentos de 53 a 68, como podemos ver no gráfico 4 :

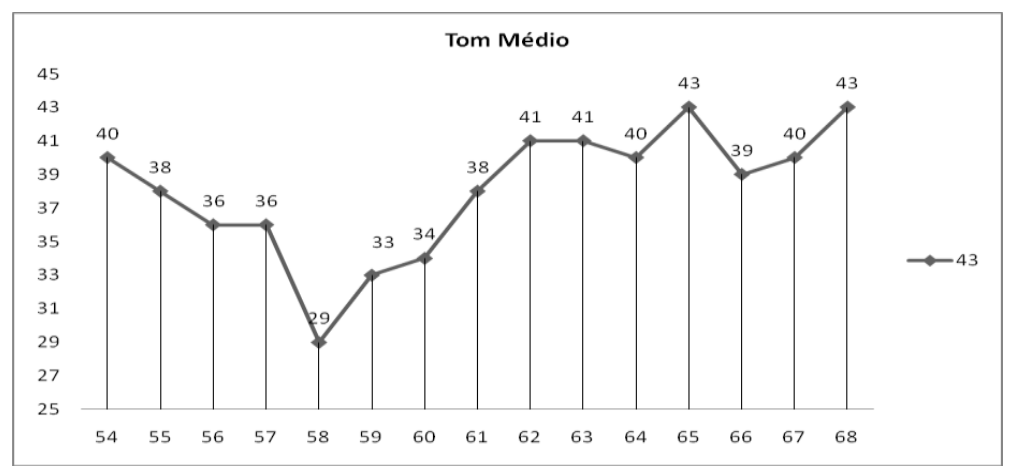

Gráfico 4. Trecho de maior variação de TM (em MIDI)

A seguir apresentamos a transcrição do trecho citado e o valor da variação (em st): 
["anda logo ooo ooo tonho!"] +5

[Falei: "Vai embora,]

[vamo embora seu Mané"]

[ele andou mais um pedacinho]

[e eu he falei heaa agora]

[é a hora] -9

[eu bato essa porteira] -5

[quero ver que que esse filho da mãe quer] -4

[cheguei::]

[peguei a porteira::] +3

[mais mandei a porteira, viu...] +3

[levei viu]

[e sai correndo] +5

[e beeem eee oooow mundo véio!]

[Hae saci veio voando "biaaau frau..."]

[e falei seu Mané me acode aqui...] +5

Apenas neste trecho podemos encontra nove variações perceptíveis das dezoito encontradas em toda a narrativa, as quais por seu turno estão espalhadas de modo aleatório pelo restante da narrativa.

\section{Considerações Finais}

Este estudo nos levou a algumas conclusões, umas delas, já observada no âmbito frasal, refere-se a uma tendência a manutenção do TM ao longo do discurso, ou seja, o falante procura sustentar em sua elocução os valores de TM sem grandes variações. Por outro podemos observar que a variação de TM pode ter um caráter semântico, de modo que a variação da entoação pode marcar uma finalização, ou mesmo a ênfase em um determinado ponto do que se diz.

Neste sentido, o que podemos observar na narrativa apresentada é que esta variação tem uma ligação relativamente 
estreita com a estrutura da narrativa. No caso é possível observar que a variação de TM nos trechos que vão de de 53-67 referem-se a ação complicadora, exposta por Labov et al. (1972), e que prevê este trecho como a parte onde os eventos do narrado de fato se desenrolam. Podemos observar também que no trecho de 57-60 o mesmo fenômeno de variação ocorre, contudo nos abre margem para uma análise de que a variação prosódica no caso tenta marcar o "pressuposto de ação", isto é, uma ação que ficaria pressuposta pela própria narração é exposta, visando enriquecê-la de detalhes ou apresentar aos falantes o que fora pensado pelo narrador ou por um das personagens no momento da ação. Referendando nossa hipótese primária.

O que nos fica claro é que, de fato, é possível se fazer uma relação entre a variação prosódica e a estrutura das narrativas orais. Embora esta seja uma questão perceptível em si pelo simples falante, devemos ressaltar que este estudo buscou fazêlo de maneira automática e baseando-se na estatística dos dados obtido, o que nos leva a reformular nossa conclusão, reafirmando que mais do que uma análise de variação dos semitons em uma narrativa oral, o estudo é também uma tentativa de se demonstrar a aplicabilidade de análise automática da entoação, assim como, é uma tentativa de traduzir através de dados numéricos, aquilo que um falante por instinto já saberia.

Outro fator não debatido, mas de suma importância para o nosso trabalho, refere-se ao uso da escala musical em MIDI, a despeito dos valores em $\mathrm{Hz}$, uma vez que nossa tentativa de se fazer a mesma análise com os valores em $\mathrm{Hz}$ mostram-se infrutíferas e demonstram todo um campo a ser explorado em futuras pesquisas: a relação entre as escalas que usamos para analisar estudos referente a fala. 